\begin{tabular}{c} 
International Journal of Engineering \& Technology, $7(2.7)(2018) 246-248$ \\
International Journal of Engineering \& Technology \\
Website: $w w w$. sciencepubco.com/index.php/IJET \\
Research Paper \\
\hline
\end{tabular}

\title{
Health care monitoring and accident tracking system based on location awareness
}

\author{
U. Sai Nishita ${ }^{1}$, K. Anusha ${ }^{1}$, K. RamyaSriSai ${ }^{1}$, Dr. Mohammed Ali Hussain ${ }^{2}$ \\ ${ }^{I}$ B. Tech Final Year, Dept. of ECM, Koneru Lakshmaiah Education Foundation, Guntur Dist., Andhra Pradesh, India \\ ${ }^{2}$ Professor, Dept. of ECM, Koneru Lakshmaiah Education Foundation, Guntur Dist., Andhra Pradesh, India \\ *Corresponding author E-mail: nishita.uppalapati@gmail.com
}

\begin{abstract}
The main focus of this paper is to design a prototype model such that it embeds different body sensors to measure parameters like body temperature, heart beat rate etc., We used an Arduino UNO board, body sensors like Heartbeat sensor and Temperature sensor to analyze the inputs from the patient's body and if there are any abnormalities regarding the pulse rate and temperature of the patient the monitoring system would give an alarm and display it on LCD. These processed values are recorded online and stored in the cloud database like Thingspeak and can be accessed through any android mobile or computer systems from any corner of the globe. This system is more useful in transport departments, especially in Buses as a very efficient and dedicated driver healthcare monitoring system. By using this model we can help all drivers who are dedicated to their work and need to be monitored due to their abnormal health conditions. Thus helping them in avoiding fatal accidents and saving the valuable lives of passengers riding along with them in the bus.
\end{abstract}

Keywords: Arduino UNO Board; Heart Beat Sensor; Temperature Sensor and GPS.

\section{Introduction}

Now day's road accidents are killing more people than some epidemics in India. But our Local and Central governments are still not taking proper initiatives regarding these issues. Giving proper awareness to common man, most importantly to Bus Drivers about taking care of their health can avoid occurring of many fatal accidents. The antiquated traffic management, transportation system are few other reasons for the frequent accidents. While advising the two-wheelers to wear helmets, and car drivers to put-on seat belts, there should be another most important rule to be followed which is monitoring of bus driver's health. By doing so it will not only save the life of driver but also save lives of several passengers travelling along with that driver. Recently many cases of accidents occurred due to driver's heart attack are seen appearing in various newspapers. So keeping this in view, a prototype model is designed using body sensors like Heart beat sensor and Temperature sensor, Arduino UNO, GPS and GSM modules to keep monitoring the pulse rate and body temperature of the patient from anywhere at any time and if any changes occur in these readings, an immediate alert messages can be sent to patient, doctor and family member through android mobiles (SMS) so that they can provide immediate medical help to the patient [3]. In case an accident occurs, it can also be tracked by using GPS and GSM modules and exact location can be identified using Google Maps[1-2]. In this case also messages are sent to nearby Police station, Hospital and to one of the family member. This can help in providing emergency medical help to the passengers and driver in case they are still in critical position. The future scope of this project is that this prototype model can be upgraded to further levels by embedding many other sensors and help detecting various other health issues of the patients.

Block Diagram

Here $9 \mathrm{~V}$ portable power supply will supply the required power for the Arduino UNO board. The GPS plus GSM modules and the body sensors (Heartbeat sensor and

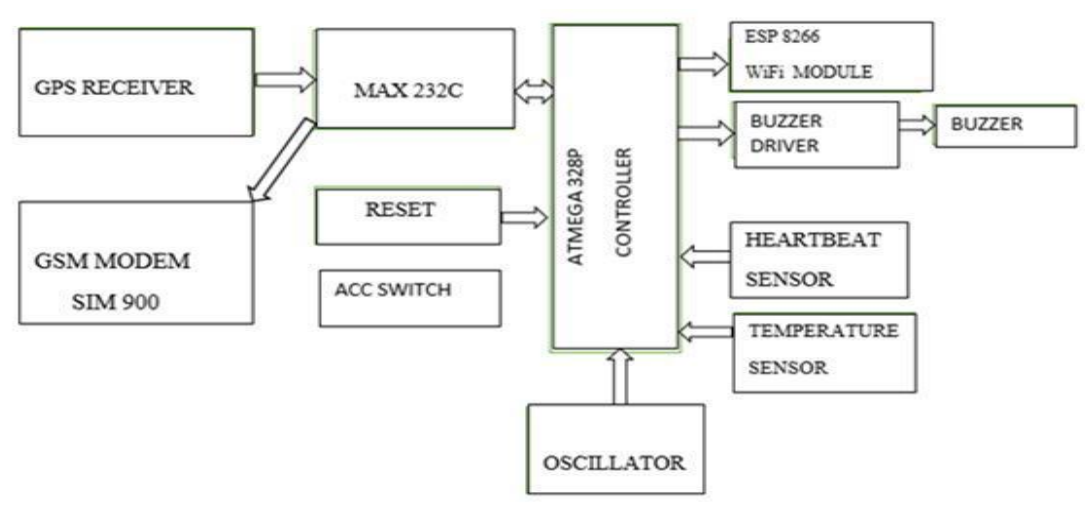


Temperature Sensor) will get power from the Arduino board. The circuit has to be first initialized by turning ON the power supply and the GPS + GSM module get automatically switched on. Then the whole prototype system waits until the GSM module gets an accurate signal and is further properly registered with the available network. Later the prototype system goes on to standby state until the sensors give a positive and required output. Once the abnormalities are detected or any accident is detected, the Arduino board acquires the detected readings from the body sensors of the patient and the current location of the vehicle with the help of the GPS module and the values recorded from the body sensors and position indicating co-ordinates i.e., of latitude and longitude are then sent as SMS to emergency services and/or contacts which the user has already stored. Thus helping in providing the emergency medical aid to the patient.

\section{Related work}

The main objective of this paper is to keep monitoring the health changes of driver while he is in his duty and provide emergency medical help if necessary. And to track his location using the GPS and GSM modules so that in case any emergency arises, immediate medical help can be provided thus his life and the lives of those passengers can be saved by avoiding accidents [4].

Accidents are occurring frequently because of driver's sudden heart attacks causing the loss of lives of many people along with the driver, this can be avoided if the driver's pulse rate and temperature is constantly and continuously monitored, this can be done easily by using body sensors [8-9]. If an accident occurs irrespective of driver's health, in many such situations immediate help cannot be provided causing major damage to many lives. This can be avoided by our proposed system model which helps in detecting the location of accident (GPS) and immediately alerting officials by sending messages to mobiles (GSM) and thus helping them to provide medical aid to the necessary.

In adverse conditions if any accident occurs, a solution can be provided by identifying the location address where the accident has taken place by sending alert messages to concerned officials like police, ambulance and family members of the respective driver. Along with the data collection from the body sensors, this model is also designed such that it can help in locating the where about of that particular driver who is using these body sensors and is under surveillance always by using GPS and GSM modules. If there are any abnormalities detected in the values given by the sensors alert messages can be sent to concerned persons like Driver himself, doctor and family member to avoid causalities and to get immediate medical aid. This prototype also provides additional facility like detecting the location of accident occurred to the vehicle due to any other cause other than driver's health condition. By using the GPS and GSM modules we can get the latitude and longitude coordinates and by using these as inputs in Google maps app[5], we can get exact location like address of where the fatal accident took place and by sending emergency messages to nearby police stations , ambulance and to driver's family member. And thus helping in providing medical help [13].

Here it is aimed, through this system, such that it serves as one of the best way to keep continuous check on the driver's health and to provide emergency help if necessary by sending alert messages (SMS) to appropriate persons by making use of wireless body sensors(WBS) that continuously detect the changes that occur in the body organs [6-7]. Through these sensors, patient can be monitored irrespective of his location and can be given immediate medical assistance and thus avoid casualties [11-12]. In other case when an accident occurs, the appropriate location of the accident can also be identified using the GPS and GSM modules and information regarding this can be sent to officials like police station and to ambulance for emergency purposes. Thus helping to reach the site as early as possible. Though the cost of this kit would be costlier since we are using body sensors and tracking location through GPS and
GSM, it will be of lot of help to drivers in avoiding severe health problems and also help in avoiding accidents occurring due to these sudden health problems. And also help in the emergency situations such as fatal accidents, by relying the information to officials even though they are in any remote place, where there is no chance for any human help.

\section{Result analysis}

\subsection{Tracking location using google map}

We can locate the exact location of the patient and the place of accident occurrence using the values of Longitude and Latitude got from GSM and GPS. Thus can save time to provide medical help [14].

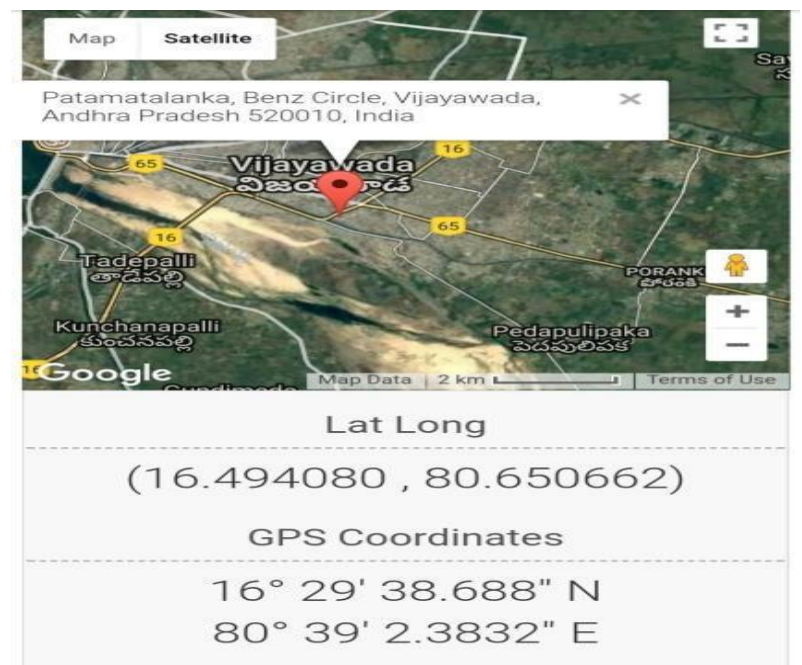

\subsection{LCD displaying pulse rate}

Here LCD is used to display the pulse rate and temperature values of the patient, which are collected from body sensors and Arduino UNO.

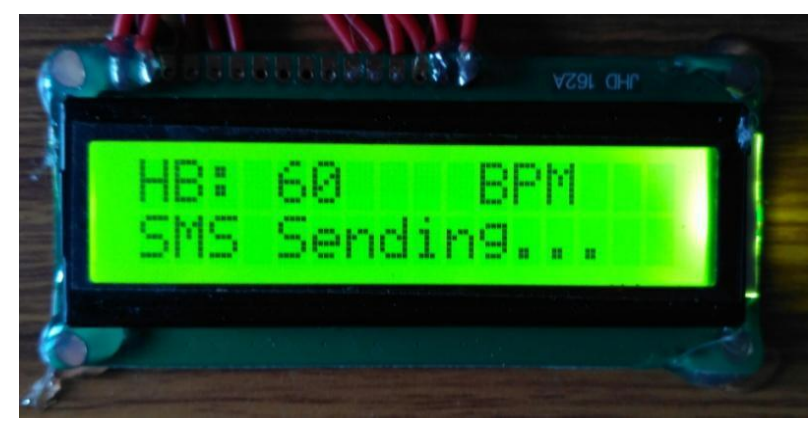

\subsection{SMS sent to android mobile}

If the values are abnormal when compared to pre-loaded values in the programming, then these values are automatically displayed on LCD and an SMS is sent to android mobiles to alert the patient, doctor, police, and family member. Thus helping them to take required measures to save patient [15].

\subsection{Graphs displayed in thingspeak}

The abnormal values recorded from the se;nsors, micro controller are sent to cloud on internet and are displayed as graphs. These values can be stored and accessed from anywhere around the globe for further reference and for providing proper medical help. 

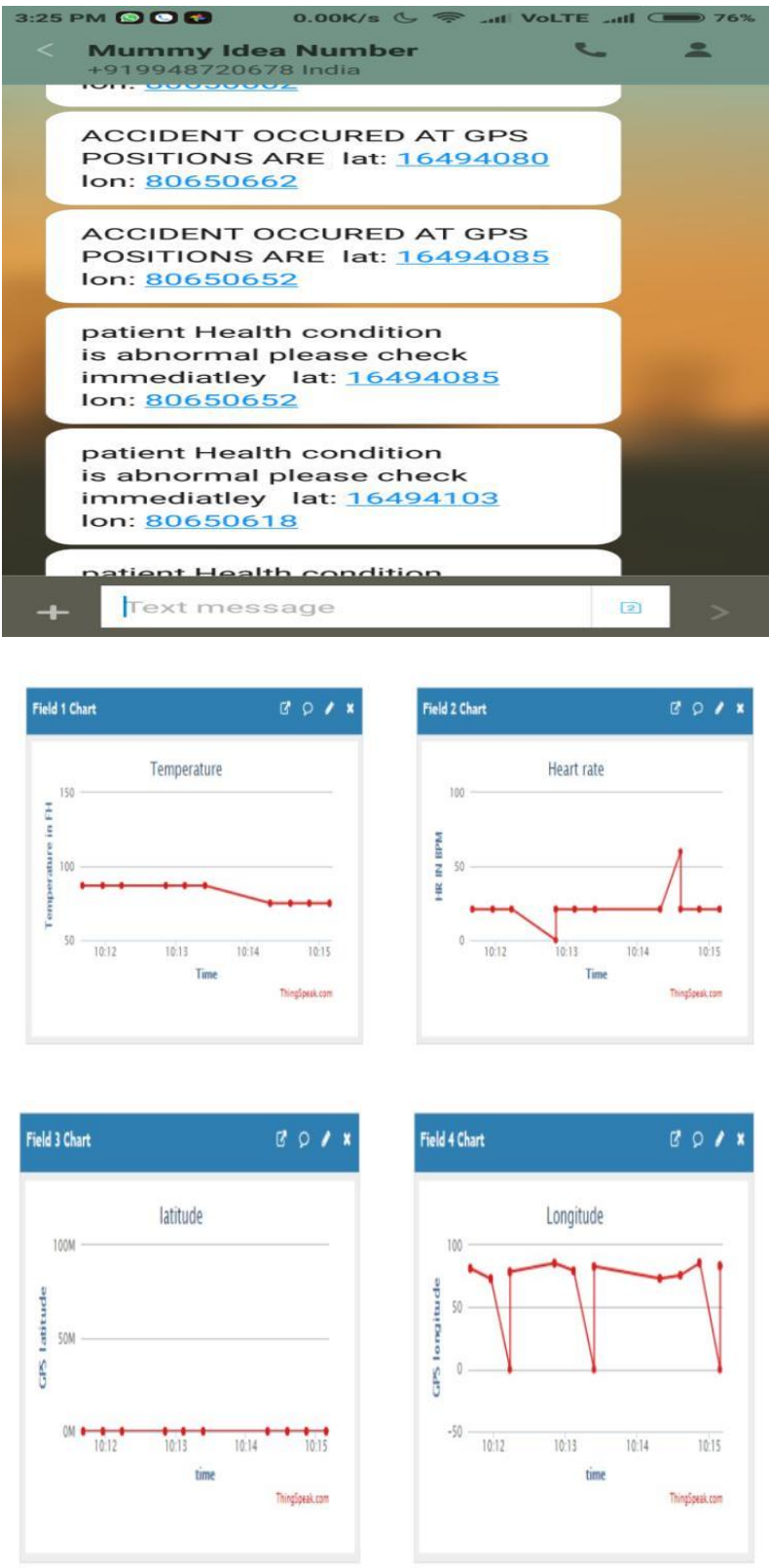

\section{Conclusion}

In this paper, a low-cost IoT prototype model to monitor driver's health care and to track the accident location is presented. The application includes body sensors embedded in Arduino UNO along with GPS and GSM devices to retrieve location and vehicle status information and send it to the other stationary module; receiving module which collects the transmitted information by SMS and process it to a compatible format to Google Earth to view the location and vehicle status online.

This can be very useful for future analysis and for reviewing of patient's health condition and avoid serious consequences like driver's death or accidents. For more versatile medical applications, this work can be extended further by including several other parameters like blood pressure monitoring systems, diabetic monitoring system.

\section{References}

[1] N. Al-Saber, O. B. Khader, and M. Al-Taee, "Remote monitoring of vehicle diagnostics and location using a smart box with Global Positioning System and General Packet Radio Service," in Proc. IEEE/ACS AICCSA, Amman, 2007, pp. 385- 388.

[2]T. S. Vardhan T. Kishore, , and L. Narayana, "Vehicle Tracking Using a Reliable Embedded Data Acquisition System With GPS and GSM", Int. Journal of Computer Science and Network Security, vol.10, no. 2, pp. 286-291, 2010

[3] J. Xiao, and Haidong Feng, " A Low-Cost Extendable Framework For Embedded Smart Car Security System", in Proc. Int. Conf. on Networking, Sensing and Control, Okayama, 2009, pp. 829- 833.

[4] V. Kulkarni, and L. N. K. Rao, "Embedded Car Security System on Face Detection". in Proc. 2nd National Conference on Information and Communication Technology, New York,2011, no. 40.

[5] J. Lin, S. C. Chen, Y. T. Shin, and S. H. Chen, "A Study on Remote On-Line Diagnostic System for Vehicles by Integrating, the Technology of OBD, GPS, and 3G," World Academy of Science, Engineering and Technology, vol. 56, pp. 435-441, Aug. 2009.

[6] S. Movassaghi, M. Abolhasan, J. Lipman, D. Smith, and A. Jamalipour, "Wireless body area networks: A survey," IEEE Communications Surveys \& Tutorials, vol. 16, no. 3, pp. 1658-1686, 2014

[7]M. Salayma, A. Al-Dubai, I. Romdhani and Y. Nasser, "Wireless Body Area Network (WBAN): A survey on reliability, fault tolerance, and technologies coexistence," ACM Computing Surveys, accepted to appear in vol. 50, no 1, March 2018.

[8] J. Bachiochi, "Light-to-frequency Conversion (Part2) TSL230RBased Pulse Oximetr", Circuit Cellar the Magazine for Computer Applications, pp. 68-71, Jan. 2005. [9]. E. N. Castellar, K. Oksanen, J. V. Looya, "Assessing Experience: Heart Rate Variability In-work Behavior and Self-report Measures", Quality of Multimedia Experience (QoMEX) 2014 Sixth International Workshop on, Sept. 18-20, 2014.

[9] Li Yong. "The Research of Monitoring System for Body Temperature of Medical Use", Modern Electrical Technology, Nov. 2006.

[10] Dirk Odenthal , Tilman Bunte , Jurgen Ackermann, "Nonlinear Steering and Braking control for vehicle rollover avoidance", Proceedings of European ControlConference, 1999.

[11] D. Alvares, L. Wieczorek, B. Raguse, F. Ladouceur, N. H. Lovell, "Development of nanoparticle film-based multiaxial Tactile sensors for biomedical applications", Sens. Actuators A Phys., vol. 196, no 1, pp. 38-47, 2013.

[12] . Figueroa, W. Solano, C. Thurman, J. Schmalzel, "A future vision of data acquisition: Distributed sensing processing and health monitoring", Proc. IMTC 2001, 20-23 May 2001.

[13] Isnandar Andang, "Study the use of accuracy image quickbird in google earth to land parcels mapping", Bandung Institute of Technology, 2008.

[14] Hoang, D.B, "Wireless technologies and architectures for health monitoring systems", Digital Society, 2007. ICDS '07, First International Conference on the 2-6 Jan. 2007 